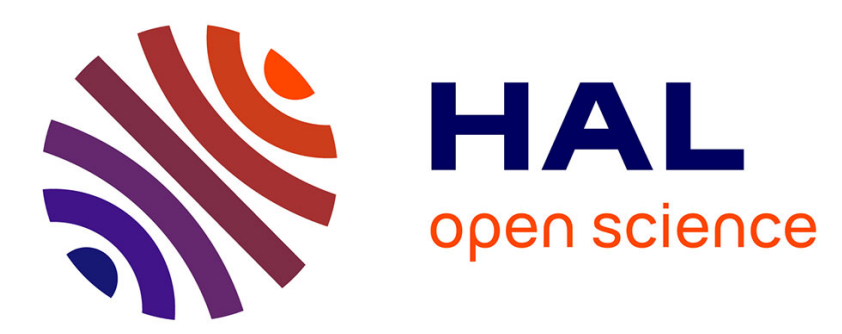

\title{
The future of University-Business Cooperation: research and practice priorities
}

Balzhan Orazbayeva, Carolin Plewa, Todd Davey, Victoria Galán-Muros

\section{To cite this version:}

Balzhan Orazbayeva, Carolin Plewa, Todd Davey, Victoria Galán-Muros. The future of UniversityBusiness Cooperation: research and practice priorities. Journal of Engineering and Technology Management, 2019, 54, pp.67 - 80. 10.1016/j.jengtecman.2019.10.001 . hal-02880384

\section{HAL Id: hal-02880384 \\ https://hal.science/hal-02880384}

Submitted on 24 Jun 2020

HAL is a multi-disciplinary open access archive for the deposit and dissemination of scientific research documents, whether they are published or not. The documents may come from teaching and research institutions in France or abroad, or from public or private research centers.
L'archive ouverte pluridisciplinaire HAL, est destinée au dépôt et à la diffusion de documents scientifiques de niveau recherche, publiés ou non, émanant des établissements d'enseignement et de recherche français ou étrangers, des laboratoires publics ou privés. 


\title{
The Future of University-Business Cooperation: Research and Practice Priorities
}

\author{
Balzhan Orazbayeva ${ }^{\mathrm{a}, 1}$, Carolin Plewa ${ }^{\mathrm{b}, *, 2}$, Todd Davey ${ }^{\mathrm{c}, 3}$, Victoria Galan Muros ${ }^{\mathrm{d}, \mathrm{e}, 4}$ \\ a Science-to-Business Marketing Research Centre, Germany \\ b Adelaide Business School, The University of Adelaide, Australia \\ c Institut Mines-Télécom Business School, France \& Science-to-Business Marketing Research Centre, \\ Germany \\ d University-Industry Innovation Network \& Global Institute on Innovation Districts, United States \\ e University-Industry Innovation Network, The Netherlands
}

\begin{abstract}
University-Business Cooperation (UBC) is an essential mechanism for advancing interests of business, universities and societies. To improve our understanding of the future of UBC research and practice, this study reports on a priority setting process comprising a two-stage research design. Qualitative research identifies a portfolio of six priority areas and 58 related topics. A quantitative step then evaluates the perceived future importance and current advancement of these topics. This approach contributes to shaping the future of UBC by identifying topics that require particular focus to maximise opportunities. The paper concludes with clear future directions for both UBC theory and practice.
\end{abstract}

Keywords: university-business cooperation, future, priorities, mixed-method

\section{Citation}

Orazbayeva, B., Plewa, C., Davey, T. \& Galán-Muros, V. (2019). The Future of University-Business Cooperation: Research and Practice Priorities, Journal of Engineering and Technology Management, 54, p67-80. 


\section{Introduction}

The importance of university-business cooperation (UBC) for innovation and education is widely recognised (Rybnicek and Königsgruber, 2019) and growing in significance as economies face increasingly competitive global markets and a race for innovation and growth (Clauss and Kesting, 2017; Sarpong et al., 2015). Worldwide, policy makers stress the importance of a strong relationship between business and higher education as a means for generating economic activity, investing significant amounts of funds to encourage UBC (Brem and Radziwon, 2017). Hence, while emphasis has been building over the last two decades, the recognition of UBC as critical to future economic and social prosperity has never been as prevalent across policy, management and academic domains as it is today (Quintana et al., 2016; Ripoll Feliu and Díaz Rodríguez, 2017). The need for a future perspective and a clear pathway for the continuous improvement of UBC as well as the maximisation of its benefits for all stakeholders are thus stronger than ever, not just in policy in practice, but also in academia. Indeed, the need for strengthening future perspectives for UBC has been recognised in literature (Galan-Muros and Davey, 2017; Mascarenhas et al., 2018), given the extensive reliance on past research in developing future priorities. For example, Teixeira and Mota (2012) extrapolate future developments upon past performance and existing strengths in a bibliometric study. Recognising the need to develop a comprehensive understanding of the broader ecosystem in which UBC value co-creation occurs (Plewa et al., 2015), an exploratory futureoriented study which takes into account the opinions of scientific as well as practice stakeholders such as industry (Kaymaz and Eryiğit, 2011), is ideally placed to achieve this. Hence, the aims of this study are:

- to identify a portfolio of areas and topics perceived as high priority in the (i) future of UBC academic research and (ii) UBC managerial practice,

- to examine the current advancement of these areas and topics,

- to evaluate the perceived future importance of the areas and topics identified,

- to determine topics that require particular focus in order to maximise the future potential of the field.

A two-stage approach was utilised. In stage one, UBC research and practice priority areas and topics were identified through brief open-ended surveys distributed to academics and practitioners. A total of 121 responses were collected, including respondents from 16 European and five non-European countries. In stage two, the future importance and the current advancement of these priority topics, for both UBC academic research and UBC managerial practice, were evaluated and responded to by 1,190 key informants through an online 
quantitative survey distributed to higher education institutions (HEIs) and businesses in 33 countries.

This study makes important contributions to UBC theory, practice and policy, providing unique insight into the future of UBC research and practice from the point of view of several groups of experts. Despite the extensive knowledge that can be gathered by using such approach, perceptions are seldom measured (Ostrom et al., 2015) thus limiting extant understanding. To date, research agendas for UBC (e.g. Ankrah and AL-Tabbaa, 2015; Perkmann et al., 2013; Rybnicek and Königsgruber, 2019) have been developed retrospectively, commonly based on a review of existing literature or based on the findings of one particular study. Although future research builds on existing knowledge, constructing a future agenda based on historical research is limited in capturing future developments. This study overcomes this limitation and is the first to set priorities for research and the practice of UBC using a futurefocused approach, aiming to facilitate the discussion of experts as to the future directions of UBC.

Moreover, a primary contribution of this study lies in its comprehensive approach to priority-setting in both research and practice. Going beyond the common focus on research priorities offered by academic papers, it elucidates priorities for managerial practice using a method that identifies both (i) their future importance ('should be') and (ii) current advancement ('is'). The 'gap' between these concepts provides a vital focus for UBC researchers and practitioners alike. Given the complexity of researching and managing UBC, the paper concludes with a specific focus on advancing the profession, critical for its future success. A primary advantage of drawing on not only academic researchers but also managerial experts working in an area under investigation lies in the ability of this approach to enhance the legitimacy of the research agenda being developed, while also implying a higher likelihood that the agenda will materialise.

In the remainder of this paper, the results of the research are detailed, outlining the overarching 'priority areas' and the topics within each area, for two domains (i) UBC research and (ii) UBC practice. Following this, future research and practice agendas are developed as a foundation for guiding forthcoming UBC research and practice.

\section{Background}

Traditionally, the government was seen to have primacy as first initiator of research and regulator, industry responsible for transfer and commercialisation of knowledge and university as a source of knowledge and developer of human capital through education (Etzkowitz and 
Leydesdorff, 2000). The three actors operated in isolation and interacted across strongly defended boundaries, with universities, and therefore UBC, generally seen as subservient to, and separated from, government-industry relations (Dzisah and Etzkowitz, 2008; Etzkowitz and Dzisah, 2008). Given the growing importance of a more collaborative approach over time, a number of models have been developed to conceptualise university and business relations in particular, including the regional innovation system, which attempts to capture innovationrelated interaction in a regional context (Laukkanen, 2003), and the closely related national innovation system proposed by Freeman (1987).

Similarly, the triple helix model was first introduced by Etzkowitz (1993) and Etzkowitz and Leydesdorff (1995) that describes the cross-sections between three helices, namely government, university and industry in the process of generating the new knowledge and spurring innovation. The triple helix has become critical in the last few decades to explain the emerging knowledge economy within policy and academic circles (Etzkowitz and Leydesdorff, 2000; Meyer, 2010) and much of the UBC literature lies on its theoretical foundations. Specifically, the triple helix reframed the importance of universities and increased their embeddedness into the economy, expanding the significance of knowledge for social development (Hladchenko and Pinheiro, 2019; Nyman, 2015). The model proposed a 'new position of the university', one in which it has an expanded and at least equal footing with government and industry in creating and leading the knowledge society, where public-private relationships play a primary role in improving national wellbeing (Abramo et al., 2012). Universities would add to the traditional core missions of education and research a third mission focused on their social and business engagement as well as entrepreneurship. More recent advances expand to quadruple and quintuple helix systems, comprising also civil society and the environment (Carayannis et al., 2018).

Prolific research has advanced our understanding of the triple helix, including the stages necessary to achieve an ideal, dynamic triple helix model (Choi et al., 2015), the evaluation of relationships across actors within the triple helix (Plewa et al., 2013; Rampersad et al., 2010), the role of individuals (Etzkowitz and Dzisah, 2008), and the development of quadruple helix ecosystems (Carayannis et al., 2018; Miller et al., 2016) among others. However, future theoretical development in this area has built substantially on a retrospective view of the research and managerial field. Given the rapid changes necessary to maximise the benefit of UBC for the social, economic, cultural and environmental advancement of our time (Skute et al., 2017), this research offers a unique future-looking perspective to steer future research, managerial and policy development. 


\section{Exploring topics defining the future of university-business cooperation}

The paper draws on the data derived from a two-stage mixed-method study of the perceptions of academic and practitioner engaged in UBC, visually represented in Figure 1.

\section{FIGURE 1 HERE}

The first stage of the research was designed to identify the topics that will define the future research and practice of UBC. While the research in this paper refers to the academic research on UBC, practice refers to the managerial practice of engaging in UBC. Exploratory qualitative research was deemed necessary initially, given not only the sparsity in research focusing on the future of UBC, but also to develop an understanding of the future of a complex phenomenon from different perspectives (Miles and Huberman, 1994), including those from the HEI and business stakeholders. Specifically, the sample consisted of scientists and practitioners in the field of UBC from both universities and businesses working in Europe and Australia, who attended relevant workshops and conferences in the area of UBC in Europe and Australia over a five-month period. A snowball sampling approach was also utilised to access relevant key informants across both regions. A total of 33 Australian and 88 European respondents began answering the first survey, leading to 81 usable answers for analysis. The final sample entails responses from Australia (25\%), the UK (17\%), the Netherlands (6\%), Germany (6\%) and Greece (6\%), as well as 12 other European and 4 non-European countries. The diverse sample included practitioners (43\%), UBC researchers (21\%) and policy makers $(9 \%)$, with other respondents not indicating their area of work.

To gather respondent perceptions openly while also enabling necessary scale, data collection utilised brief surveys comprised of three open-ended questions asked both in relation to UBC research and practice. To avoid uninformed responses, participants were able to answer all questions or focus on those questions they deemed most relevant to their area of expertise. The following three questions were addressed: (1) What are the most important topics researchers and practitioners need to address in the next five years to advance UBC? (2) Why are these topics particularly important? (3) Which approaches are needed for the topics to be addressed?

This research focuses on the first question, as the survey responses served as the basis for identifying and developing future priorities for UBC practice and research. Thematic analysis was utilised to identify broad themes emerging from the data. Using Lincoln and Guba's (1985) constant comparative method, the authors coded the data independently first, 
seeking to identify future research and practice areas; before comparing and discussing their results in a debriefing process in which any variations in coding were discussed, leading to the agreed and final results reported here. At the completion of the coding process for the individual priority topics, the same process was undertaken to determine the labelling of priority areas that reflect the identified topics. Hence, the authors first grouped topics and proposed labels individually before comparing and discussing the proposed priority areas.

The iterative process of comparing, discussing, consolidating and refining the areas led to the identification of 58 topics ( 28 research +30 practice) across six areas for the future of UBC, namely Policy Frameworks, Measures and Key Performance Indicators (KPIs), Engagement, Strategy and Approach, Entrepreneurship, as well as Context. The former two areas emerge as relevant only for future UBC research, not for practice. While the Policy Framework area reflects the future role of government, government policy and funding within the wider UBC ecosystem, topics classified in the area of Measures and KPIs relate to the need for metrics, systems and measurement professionalising our understanding and development of UBC.

Four priority areas emerge for both future UBC research and practice. The area of Engagement includes a large number of topics related to the improvement of the interface between university and business actors, with a particular focus on perceptions, attitudes and the management of this interface. The Engagement area is connected to Strategy and Approach topics, which specifically relate to strategies and approaches known to encourage UBC. The Entrepreneurship area comprises both student and academic entrepreneurship topics, as well as related support structures. The Context related area notes the importance of recognising and understanding specificities in relation to national, regional and industry contexts. Figure 2 offers a visual representation of the priority areas across UBC research and practice.

\section{FIGURE 2 HERE}

Considering the future of UBC research, topics such as the development of partnership modes and models for UBC, methods for partner identification and academic training emerge commonly amongst the answers in this initial qualitative investigation. Furthermore, the need to broaden our understanding of the extensive UBC ecosystem emerges in the results as an important direction for future research, as are focus areas of measuring the impact of UBC and providing evidence of such impact. Common perceptions of future priorities emerged across respondents from Europe and Australia. Pinpointing some focus areas, European respondents 
focused more strongly on examining motivations for engaging in UBC, also focusing on UBC challenges, as well as stakeholder roles and stereotypes. Australian respondents place a stronger emphasis on the development of partnering models, as well as on investigating skill development, communication models and KPIs for universities and their staff. Respondents noted a variety of reasons for why they identified certain research priorities, including the need for (1) evidence, evidence-based models and metrics, (2) understanding how and why things work or do not work, (3) professionalism in the research in, and management of UBC, (4) thought leadership in rethinking and changing innovation and engagement over time, as well as (5) measurement of the impact and success of UBC initiatives.

Specific to UBC practice, a stronger focus on long-term relationships in UBC, driven through a greater alignment of interests, better mechanisms supporting UBC, improved monitoring of activities, as well as better stakeholder management and governance emerged as central to the future. The results suggest that UBC is expected to grow particularly in economically weaker regions, and outside of the technical faculties. Developing a much better understanding of UBC, embracing entrepreneurship and a focus on dual study programs and other student-centred UBC activities also feature strongly in the qualitative responses. While most topics emerged across samples from both Europe and Australia, the results indicate a particularly strong interest of European respondents in entrepreneurship, including start-ups and spin-offs, the establishment and management of partnerships, as well as a greater focus on SME engagement. Australian participants focused more strongly on the future priorities of developing understanding across relevant stakeholder groups, the promotion of UBC to increase awareness, as well as IP and expectations management.

The results show a great depth in the reasoning behind the practice priorities identified by respondents, which can be summarised in six key points:

- Sustainability, given the need to further UBC as a foundation for the competitive advantage of universities and business but also for the economic growth of a region;

- The need to develop human capital, with UBC important to support skill development, student employability and lifelong learning;

- The need for continuous improvement, and thus not only to do more but do it smarter and more efficiently;

- The awareness of engagement opportunities and benefits, as well as advanced general visibility of UBC within the society;

- The need to experience different stakeholder perspectives and cultures; 
- The need to establish a professional approach to UBC, including customised and innovative collaboration models within and across organisations.

\section{Priorities for university-business cooperation}

The second research stage aimed at empirically determining perceptions of UBC practitioners and researchers relating to the future importance and current advancement of priorities identified in the first stage. Data was gathered via a web-based survey targeted at academics, technology transfer professionals and senior management of European HEIs as well as business representatives. The survey was translated into 25 languages and distributed to HEIs and businesses in 33 countries, those in the European Economic Area (EEA) and candidate members to the European Union.

Survey participants were asked to rate each of the previously identified 58 topics in UBC research and practice in terms of their (i) importance for the future, and (ii) current advancement; on a scale from 1 = "not at all important" and "not at all advanced", to 7 = "very important" and "very advanced" respectively. Specifically, they were asked: (i) How important are the following priorities for advancing UBC practice/research in the future? and (ii) How far advanced is current UBC practice/research in respect to the following priorities? The survey led to a final usable sample of 230 responses from HEI managers, 447 from academics, 135 from knowledge transfer professionals (KTPs) and 378 from business. The four respondent groups addressed the practice priorities but only academic addressed the research priorities.

The following sections detail the 58 individual topics ordered under the six priority areas across both UBC research and practice domains. Specifically, all topics are examined as per respondent perceptions of both the future importance and current advancement of individual priority areas and related topics. Notable gaps (on a 7-point scale) between the future importance and the advancement of that topic are outlined.

\section{Research domain}

The analysis of research priorities identified in the qualitative stage provides a clear picture guiding the future of UBC research. The current advancement and perceived future importance of each topic were assessed by European academics, who are close to both the context of UBC and relevant research. For all 28 topics ranked in this study, current advancement ('is') lags behind the future importance ('should be'). A paired samples t-test confirmed significant differences between the two means for all topics at $99 \%$ level (p value 
<0.000.) The results thus call for research across all priority areas, given that the identified topics have not been suitably covered yet. However, the lag of current advancement differs significantly across topics. Results are outlined in Tables 1 and 2.

\section{Table 1 HERE}

\section{Policy frameworks}

The largest gap between future importance and current advancement is in the area of Policy Frameworks, suggesting that relevant policies are central to the future development of $\mathrm{UBC}$ research. The highest priority topic for UBC research is exploring the effect of university funding model changes since it has the highest future importance and the largest development gap. Despite an ongoing debate regarding the rationale for resource allocation to university research (Dougherty et al., 2016) and the funding system for higher education institutions in general (Jongbloed and Vossensteyn, 2016), this issue remains underexplored. How this funding, alongside other elements, contributes and relates to our understanding of the broader ecosystem of UBC as another important policy framework topic for future research to examine. Such research on ecosystems can build on our extant understanding of the UBC framework (Galan-Muros and Davey, 2017).

\section{TABLE 2 HERE}

Whereas according to some authors the interplay of the triple helix components remains dynamic and ambiguous, calling for further research (Ivanova and Leydesdorff, 2014; Leydesdorff et al., 2017; Leydesdorff and Ivanova, 2016), our findings suggest that the government's role in the triple helix would benefit from further research but to a lesser extent than other topics examined in this study. An extant literature stream is devoted particularly to the role of government in relation to UBC and triple helix (Belkhodja and Landry, 2007; Etzkowitz and Leydesdorff, 1995, 2000; Etzkowitz and Zhou, 2008) investigating different aspects of the government's involvement, including the development of UBC policies and funding (Goldfarb, 2008; Mars et al., 2012; Nyman, 2015).

\section{Measures and KPIs}


Measures and KPI emerges as the second most relevant research priority area, given the evident gap between current advancement and future importance on average across its six topics. Specifically, the need to understand the impact of UBC on research is the topic with the second highest future importance and the second highest priority topic for future research. These findings demonstrate that more research is needed to broaden the knowledge on the consequences and impacts of academic engagement (Ankrah and AL-Tabbaa, 2015; Perkmann et al., 2013). The effect of universities' third mission on the other two missions, in particular research, remains ambiguous and requires further investigation. Research evidence on this topic will be critical in building the foundation for decision making of HEIs' top management to adapt research agendas and related administrative procedures. In addition, the measurements assessing the state and the advancement of UBC based on a valid definition of UBC success are necessary to provide direct implications for policy and management of collaborative activities (Healy et al., 2014). However, the measuring of impact flowing from UBC is complex given the multi-faceted nature of the phenomenon (Galan-Muros and Davey, 2017; Perkmann and Walsh, 2007). Hence, it is challenging to capture through simple metrics and indicators, given the various levels and types of interactions, channels through which this interaction is possible, and a range of diverse factors influencing outcome generation and the way collaboration is developed and maintained.

Furthermore, evolving research on this area reports that existing metrics and performance indicators are not adequately comprehensive and therefore are not capable to properly assess the impact of UBC (Perkmann et al., 2013; Ramos-Vielba et al., 2010; Tijssen et al., 2009; Tijssen et al., 2016). Thus, there is a need to ensure the suitable measurement of the impact and success of initiatives undertaken by universities and businesses (Kaklauskas et al., 2018), particularly from an industry perspective. Specifically, an investigation of how business identify and evaluate suitable researchers or teams as well as an evaluation of how business define success in UBC emerge as two of the key research topics for the future agenda, building on earlier work examining how firms should evaluate success in university-industry alliances (Perkmann et al., 2011). As earlier research has shown that academics perceive themselves to receive the least amount of benefits from UBC (Davey et al., 2011), there is also a potential need to understand UBC success measures for academics and other UBC stakeholders. This research would support the development of KPI systems for academics related to UBC, a topic that results suggest is in need of further research.

\section{$\underline{\text { Strategies and approaches }}$}


Comprising five topics, the area Strategies and Approaches emerges as the (equal) third highest research priority. A significant gap is evident between the future importance and current advancement of innovative business and partnership models for UBC as well as for HEI engagement with SMEs. Considering that more than $93 \%$ of enterprises in the non-financial business sector in Europe are SMEs ${ }^{1}$, their involvement in UBC is of a great importance. However, they commonly lack human and financial resources which often limit their capacity to undertake their own R\&D (Lichtenthaler, 2005; Narula, 2004). Contrarily, large firms are traditionally more engaged in UBC as they are more likely to have higher technological development and higher absorptive capacity (Darabi and Clark, 2012; Muscio, 2007).

The understanding of both business and HEI motivations to engage in UBC has seen important advancements in recent years. Generally, the extent of UBC is affected among others by the personal motivation of individuals to engage in UBC, whether it is academics (Ankrah et al., 2013; D'Este and Perkmann, 2011; Dan, 2013) or business representatives. Given the importance of such motivations now and in the future, a range of authors have explained motivations for entering into relations with universities (Ankrah et al., 2013; Dan, 2013; Fan et al., 2015; Metcalfe, 2010; Siegel et al., 2003). Nevertheless, our results indicate the continuing need to explore business motivations for UBC in particular (Freitas and Verspagen, 2017; Han and Yim, 2018) and how academics are trained for UBC, indicating a need to better understand academic personnel development in the context of cooperation with other sectors.

\section{$\underline{\text { Context }}$}

The qualitative stage identified only one Context related topic, suggesting the need to further investigate UBC across different industry sectors and cultural contexts. Specifically, such research will enable wider application and generalisation, allowing stronger theoretical development and managerial implications. Varying transfer patterns suggest that the diverse channels to exchange knowledge and technology still need to be explored across sectors and disciplines that possess different learning and technological opportunities (Bekkers and Bodas Freitas, 2008; Schartinger et al., 2002). The importance of examining differences across countries and industrial sectors aligns with recent calls for future research (Pavlin, 2016).

\section{Engagement}

\footnotetext{
${ }^{1}$ The vast majority of SMEs are micro enterprises with less than 10 employees - such very small firms account for almost 93\% of all enterprises in the non-financial business sector (Annual Report on European SMEs, 2015/2016 - SME Recovery Continues).
} 
The 11 Engagement topics vary in the perceived importance and current advancement. Respondents indicated that research on how to encourage academic engagement should be a future priority. The prevailing discussion around academics motives to cooperate with business is led by the belief that academics are driven mainly by extrinsic for-profit motives (Lam, 2011), in particular for R\&D commercialisation. However, research on the most effective incentives to encourage academics to cooperate with business remains limited. Finally, the need to understand the attitude and skills of great UBC practitioners emerges as another important area for future research.

On the other hand, the results suggest a somewhat advanced understanding of cultural barriers. Literature has commonly considered the cultural divide between distinct types of organisations as a significant barrier that has an ultimate impact on the way their collaboration happens (Bruneel et al., 2010; Davey et al., 2016b; Malik, 2013). Differences in the university and business institutional cultures (Rajalo and Vadi, 2017), expressed in diverse behaviours and working styles (Bstieler et al., 2015; Hemmert et al., 2014; Lahorgue, 2009), can potentially impact the development of trustful relationships (Bellini et al., 2018). This might have caused the prolific attention given to understanding cultural barriers. Nonetheless, there is a lower understanding of the needs and roles of all stakeholders in UBC, a factor that would further clarify expectations across the cultural divide.

\section{Entrepreneurship}

Respondents perceive Entrepreneurship at universities as the most advanced research priority area. It encompasses two topics; student entrepreneurship, which has received significant research attention, and academic entrepreneurship, which would highly benefit from further research. Particularly, the findings highlight the need to explore more effective ways of cultivating academic spin-offs (Rasmussen and Wright, 2015) to exploit technology and knowledge potential of universities through the promotion of academic entrepreneurship. As entrepreneurship is increasingly recognised as part of the university's role (Bosma and Levie, 2010; Davey et al., 2016a), its execution through academic spin-offs represents promising future research avenue.

\section{Practice domain}

UBC has received significant interest not only in academia, but also across management circles as a mechanism to address a numerous societal and organisational challenges countries 
face today (Ankrah and AL-Tabbaa, 2015; Berbegal-Mirabent et al., 2015; Sandberg et al., 2015). However, it remains an indistinct professional field, activated and developed by a wide range of individuals across multiple functions and highly fragmented across many countries (Davey et al., 2011). To develop clear future directions for UBC practice, a quantitative analysis was undertaken to assess 30 ranked practice topics. Perceptions of the future importance and current advancement are outlined in Tables 3 and 4, and paired samples t-tests confirmed significant differences between the means for all topics at $99 \%$ level ( $\mathrm{p}$ value $<0.000$ ). In comparison to research priorities, a lower gap between current advancement and future importance emerges for practice, suggesting that practice is somewhat better aligned with future requirements. Moreover, the significantly lower standard deviation shows a greater agreement on the current and future status of the topics across the priority areas in the practice domain.

Given that the practice domain is examined drawing on responses from HEI management, KTPs, academics and business, some specific insights in relation to these respondent groups should be noted. Specifically, ANOVA tests show a close alignment in perceptions relating to the future across all four groups. Indeed, significant differences only emerge between the perceptions of business (mean 5.5) and KTPs (mean 5.8) in relation to the future importance of strategies and approaches, between academics (mean 5.6) and KTPs (mean 5.9) in relation to engagement, as well as between KTPs (5.9) / HEI management (mean 6) and academics (mean 5.6) in relation to entrepreneurship. No significant differences emerged between groups in relation to the future important of context.

HEI management and KTPs perceive the current advancement of topics similarly, and so do business and academics. The former two groups score current advancement higher across the future advancement of all areas but context. Specifically, ANOVA results show no significant difference between the means of HEI and KTPs across the themes Strategies and Approaches, Engagement and Entrepreneurship (HEI means 3.6, 3.7, 3.9 respectively; KTPs means 3.8, 3.8, 3.8 respectively), not between the businesses (means 3.2, 3.2, 3.2 respectively) and academics (means 3, 3.2, 3.1 respectively). Significant differences emerged for the other mean. In relation to context, the perceptions of HEI management (mean 3.5) is significantly higher to both academics (mean 3) and business (mean 3.1), with no other significant differences recorded.

TABLE 3 HERE

TABLE 4 HERE 


\section{$\underline{\text { Context }}$}

The practice domain only comprises two Context related topics. Results suggest a strong need to foster UBC in economically weak regions. This importance arises due to the central role of HEI in the development of the region and in regional 'smart' specialisation, including region clusters, networks and tacit knowledge exchange (Gunasekara, 2006).

\section{Strategies and approaches}

Strategies and Approaches comprises 10 topics. The need to enable academics to take meaningful amount of time for UBC is the highest priority for practitioners. This finding aligns with some UBC literature reporting time constraints as a major barrier within HEIs (Ramli and Senin, 2015; Wilson, 2012). The issue of devoting sufficient time for UBC is often explained by the multitude of responsibilities and duties performed by academics, such as teaching, supervising students, research and administration.

The importance of enabling conditions aligns with the need for implementing a research culture open to UBC, which emerges as an important topic for future practice. The traditional research culture at universities is dominated by the overwhelming institutional rules governing knowledge generation and transfer processes (Partha and David, 1994). These are often associated with high levels of bureaucracy and inflexibility (Hughes, 2011; Hülsbeck et al., 2013; Rhodes et al., 2008), challenges related to IP ownership (Bekkers and Bodas Freitas, 2008; Bruneel et al., 2010) and effective communication between stakeholders (McNichols, 2010). A culture of UBC across the HEI would relate to another topic of interest, namely fostering UBC beyond a mere technology focus, as well as to the continued development of mechanisms that support UBC. Cooperation between HEIs and companies in its nature is a complex phenomenon requiring high-performing mechanisms. For example, relevant topics are the development of a comprehensive and coordinated approach to business, approaching UBC with flexibility and transparency, and promoting UBC proactively.

\section{Entrepreneurship}

The area of Entrepreneurship at HEIs comprises four topics. Specifically, the results show a lag in developing an entrepreneurial mind-set in HEI staff and students. Notwithstanding the importance of entrepreneurship for modern economies, the role of HEIs in building and stimulating entrepreneurial mind-sets remains uncertain (Fayolle and Gailly, 2008). More broadly, respondents identified a need for HEIs to better promote entrepreneurship amongst 
their staff. While acting entrepreneurially is seen as part of the role of all actors within the university (Gibb et al., 2012; Gibb and Hannon, 2006), a need for further development of an innovative culture and entrepreneurial behaviour among academics has also been recognised in the literature (Dan, 2013).

Following the discussion about the importance of the entrepreneurial development among university stakeholders, the results indicate that the facilitation of student entrepreneurship at the HEI is relatively well advanced and with a less pressing need for action. Indeed, a body of literature is signalling an increasing attention of universities in enhancing entrepreneurial activities among students and graduates (Bercovitz and Feldman, 2006; Farhangmehr et al., 2016; Maresch et al., 2016). The entrepreneurial education of students is generally one of the most recognised roles for HEIs in the topic of entrepreneurship (Bosma and Levie, 2010; Davey et al., 2016a). The rate of student start-up creation is generally higher than academic entrepreneurship (Berggren and Lindholm Dahlstrand, 2009), which can be explained by the increased support of universities (Hisrich, 2006) and the legal barriers that academics often face.

\section{Engagement}

With 14 Engagement topics, this area is the largest of the practice domain. Building strong relationships between HEIs and business remains critical not only for researchers, but also for practitioners. European practitioners agree that in order to move the UBC field forward, more attention is needed to the "relationship" component; a highly complex and fragmented topic (Plewa and Quester, 2007). Similar to the research priorities, fostering HEI cooperation with SMEs emerges as an important topic for the future of UBC practice with a high need for further development. University linkages remain underdeveloped in many countries despite being an effective instrument for advancing business innovation potential in SMEs as well as a channel for promoting job opportunities available at the SME sector (Wilson, 2012). Newly graduated job hunters tend to seek employment in large national and international corporations rather than SMEs, which are also traditionally less formal in their staff selection process (Wilson, 2012).

UBC is more recently proving itself as a promising instrument for preparing students for their future careers and provision of more relevant higher education (Hasanefendic et al., 2016; Ishengoma and Vaaland, 2016; Pujol-Jover et al., 2015) and such developments are mirrored in the results of this study. It outlines the use of UBC as a tool to enhance student employability as one of the most advanced topics but still highly important for future practice. 
HEIs should thus continue and further develop their engagement with companies to ensure students' contacts to their potential future employers and, in turn, facilitate the development of workplace relevant skills and competences (D'Este and Perkmann, 2011; Ishengoma and Vaaland, 2016; Orazbayeva et al., 2019).

Other topics in need of further development entail the successful management of stakeholders and their expectations, as well as the promotion of UBC benefits to business and the wider community. Furthermore, future developments require HEIs to develop a recruitment strategy for UBC. While the employment of qualified staff emerged as somewhat well developed in the area of technology transfer, the importance of promoting career perspectives for these specialists remains in need for further development.

\section{Discussion}

This study offers important contributions to the development of future priorities for research and practice by drawing on expert opinions. It is the first study to set priorities and future directions for research on UBC by focusing on the future rather than the past, an approach that enhances the legitimacy of the research agenda while also suggesting a strong likelihood that the agenda will be utilised for future advancements. Specifically, this paper moves the field forward by identifying research topics and related priority areas, generating a springboard for researchers, so that they can easily identify the key areas demanding further development as they seek to advance theoretical developments in UBC. Drawing on the gap identified between current advancement and future importance, future research should seek to advance theoretical and empirical development in the areas of Measures and KPIs as well as Policy Frameworks. This indicates the role for UBC research in identifying indicators to measure and evaluate UBC and a storyline for its ability to amplify the impact of HEIs. Moreover, academics embrace the need for research to underpin policy development, especially in assessing how HEI funding models and UBC relate. Based on the findings of this study, a comprehensive research agenda is offered in Table 5 .

\section{TABLE 5 HERE}

Another primary contribution of this study lies in its future approach to priority-setting for UBC practice; going beyond the focus on future research. While results in the qualitative stage suggest a large number of potential development topics in the areas of Engagement as well as Strategies and Approaches, stage two identified that practice topics in need of future 
development are multi-fold. They are related to people and promoting an expanded UBC mindset, to being entrepreneurial, considering UBC beyond technology, developing a research culture open to UBC or UBC involving SMEs or businesses in economically weak regions. The other most pressing practice priorities are related to providing mechanisms and incentives for UBC, supporting UBC with flexible, transparent and coordinated mechanisms as well as ensure that academics have the time necessary to engage in it. A final stream of topics notes the important practical need to recruit the right people for UBC and provide career paths for academics undertaking UBC and relevant support staff.

This study offers important insights into the role of the quadruple helix. In particular, it suggests that to move UBC forward, practice has to be considered and advanced across all actors. For example, HEIs must develop a sustainable culture for UBC. This involves prioritising the recruitment of academic and support staff with UBC competencies to develop a better understanding and cultural fit with industry, allocating staff time for collaborating and implementing appropriate mechanisms to support UBC are HEI mechanisms that can also help to foster UBC. This also means embracing a broader role in society, including better stakeholder management, more transparent and flexible ways to cooperate with SMEs as well as engaging with industry to a greater degree in education, is vital to take forward UBC practice and improve student employability. Focussing more specifically on developing entrepreneurial mind-sets in staff, academics and students is fundamental to achieving this. Underpinning these activities, a more sophisticated strategy for stakeholder management is needed to ensure the future promise of UBC is realised. Future practice priorities are illustrated in Table 6 in the form of questions to be considered by stakeholders within the triple helix, in particular HEIs, representing a future practice agenda for UBC.

\section{TABLE 6 HERE}

Interestingly, varying priorities emerged in the research and practice domains. While respondents believe that future research priorities lie to a greater degree on documenting or quantifying policy-levels antecedents or the outcomes and impacts resulting from UBC, practice priorities should focus more strongly on how people on both sides can be best supported to develop UBC relationships. For example, the engagement of SMEs is a topic relevant for both the research and practice domains, the development of innovative partnership models with SMEs noted as a central research priority, whilst practice focused on the importance of fostering HEI cooperation with SMEs. 
The interconnectedness of research and practice will be of critical importance for the future development of both domains. Organisational learning theory and Nonaka's knowledge development paradigm (Nonaka, 1994) demonstrates the importance of research informing practice and vice versa, the foundation of UBC as a context. To provide an example for mutual learning emerging from this study, practice priorities suggest that to better support the operational realm, research could focus on methods for influencing the academic culture and mind-sets and for engaging with SMEs, regions and in non-technical faculties. Aligned to this, research priorities suggest that practice could be underestimating the need for the development of models and impact measures to influence academic cultures and mind-sets.

\section{Conclusion}

With UBC central for the future prosperity of nations, organisations and individuals, a clear path towards developing the future of both UBC research and practice is critical. While this research outlines future directions based on expert opinions, impact will only be felt if we not only understand but also act on the future importance of both research and practice priorities, as well as related policy levers. Only the joint efforts of UBC researchers and practitioners will enable a leap forward for everyone involved.

This study is not without limitations, in line with research following similar aims in other areas of research (Ostrom et al., 2015). Although the authors made considerable efforts to engage a wide variety of UBC experts across both research and practice domains, participation in this survey was voluntary. Hence, results cannot be generalized across the wider population of UBC stakeholders. Indeed, with respondents potentially focused on topics on top of their mind either due to current or anticipated areas of activity, bias in the form of over- and under-emphasis of certain topics is likely and specific to the respondents. Furthermore, acknowledging the lack of feedback from policy makers as a limitation of this study, researchers are encouraged to extend this study by investigating the perspective of policy makers and other relevant stakeholders, such as students, consultants and industry associations. In particular, an advanced understanding of the interplay of the three UBC areas of research, policy and practice is necessary. Another limitation lies in the geographic constraints of the sample. While the first qualitative stage of the study comprised respondents from both Europe and Australia, the data collection of the second quantitative stage was limited to Europe. Nevertheless, the inclusion of responses from 33 countries ensures input from a variety of contexts and settings. 


\section{References}

Abramo G, D’Angelo CA and Solazzi M (2012) A bibliometric tool to assess the regional dimension of university-industry research collaborations. Scientometrics 91(3): 955-975.

Ankrah S and AL-Tabbaa O (2015) Universities-industry collaboration: A systematic review. Scandinavian Journal of Management 31(3): 387-408.

Ankrah SN, Burgess TF, Grimshaw P, et al. (2013) Asking both university and industry actors about their engagement in knowledge transfer: What single-group studies of motives omit. Technovation 33(2): 50-65.

Bekkers R and Bodas Freitas IM (2008) Analysing knowledge transfer channels between universities and industry: To what degree do sectors also matter? Research Policy 37(10): 1837-1853.

Belkhodja O and Landry R (2007) The Triple-Helix collaboration: Why do researchers collaborate with industry and the government? What are the factors that influence the perceived barriers? Scientometrics $70(2)$ : 301332.

Bellini E, Piroli G and Pennacchio L (2018) Collaborative know-how and trust in university-industry collaborations: Empirical evidence from ICT firms. The Journal of Technology Transfer: 1-25.

Berbegal-Mirabent J, Sánchez García JL and Ribeiro-Soriano DE (2015) University-industry partnerships for the provision of R\&D services. Journal of Business Research 68(7): 1407-1413.

Bercovitz J and Feldman M (2006) Entpreprenerial universities and technology transfer: A conceptual framework for understanding knowledge-based economic development. The Journal of Technology Transfer 31(1): 175-188.

Berggren E and Lindholm Dahlstrand $\AA$ (2009) Creating an entrepreneurial region: Two waves of academic spin-offs from Halmstad University. European Planning Studies 17(8): 1171-1189.

Bosma N and Levie J (2010) Global Entrepreneurship Monitor 2009. Final Report.

Brem A and Radziwon A (2017) Efficient Triple Helix collaboration fostering local niche innovation projects-A case from Denmark. Technological Forecasting and Social Change 123: 130-141.

Bruneel J, D'Este P and Salter A (2010) Investigating the factors that diminish the barriers to university-industry collaboration. Research Policy 39(7): 858-868.

Bstieler L, Hemmert M and Barczak G (2015) Trust Formation in University-Industry Collaborations in the U.S. Biotechnology Industry: IP Policies, Shared Governance, and Champions. Journal of Product Innovation Management 32(1): 111-121.

Carayannis EG, Grigoroudis E, Campbell DFJ, et al. (2018) The ecosystem as helix: An exploratory theorybuilding study of regional co-opetitive entrepreneurial ecosystems as Quadruple/Quintuple Helix Innovation Models. R\&D Management 48(1): 148-162.

Choi S, Yang JS and Park HW (2015) Quantifying the Triple Helix relationship in scientific research: Statistical analyses on the dividing pattern between developed and developing countries. Quality \& Quantity 49(4): 1381-1396.

Clauss T and Kesting T (2017) How businesses should govern knowledge-intensive collaborations with universities: An empirical investigation of university professors. Industrial Marketing Management 62: 185198.

D'Este P and Perkmann M (2011) Why do academics engage with industry? The entrepreneurial university and individual motivations. The Journal of Technology Transfer 36(3): 316-339.

Dan MC (2013) Why should university and business cooperate? A discussion of advantages and disadvantages. International Journal of Economic Practices and Theories 3(1): 67-74.

Darabi F and Clark M (2012) Developing business school/SMEs collaboration: The role of trust. International Journal of Entrepreneurial Behavior \& Research 18(4): 477-493.

Davey T, Baaken T, Muros VG, et al. (2011) The state of European University-business cooperation: Final report - Study on the cooperation between higher education institutions and public and private organisations in Europe. Münster: Science-to-Business Marketing Research Centre.

Davey T, Hannon P and Penaluna A (2016a) Entrepreneurship education and the role of universities in entrepreneurship. Industry and Higher Education 30(3): 171-182.

Davey T, Rossano S and van der Sijde P (2016b) Does context matter in academic entrepreneurship? The role of barriers and drivers in the regional and national context. The Journal of Technology Transfer 41(6): 14571482.

Dougherty KJ, Pheatt L, Natow RS, et al. (2016) Performance funding for higher education. JHU Press.

Dzisah J and Etzkowitz H (2008) Triple helix circulation: The heart of innovation and development. International Journal of Technology Management \& Sustainable Development 7(2): 101-115.

Etzkowitz H (1993) Enterprises from science: The origins of science-based regional economic development. Minerva 31(3): 326-360. 
Etzkowitz H and Dzisah J (2008) Rethinking development: Circulation in the triple helix. Technology Analysis \& Strategic Management 20(6): 653-666.

Etzkowitz H and Leydesdorff L (1995) The Triple Helix--University-industry-government relations: A laboratory for knowledge based economic development. EASST Review 14(1): 4-9.

Etzkowitz H and Leydesdorff L (2000) The dynamics of innovation: From National Systems and "Mode 2" to a Triple Helix of university-industry-government relations. Research Policy 29(2): 109-123.

Etzkowitz H and Zhou C (2008) Introduction to special issue Building the entrepreneurial university: A global perspective. Science and Public Policy 35(9): 627-635.

Fan X, Yang X and Chen L (2015) Diversified resources and academic influence: Patterns of university-industry collaboration in Chinese research-oriented universities. Scientometrics 104(2): 489-509.

Farhangmehr M, Gonçalves P and Sarmento M (2016) Predicting entrepreneurial motivation among university students: The role of entrepreneurship education. Education + Training 58(7/8): 861-881.

Fayolle A and Gailly B (2008) From craft to science: Teaching models and learning processes in entrepreneurship education. Journal of European Industrial Training 32(7): 569-593.

Freeman C (1987) Technology policy and economic performance: Lessons from Japan. London, New York: Frances Printer Publishers.

Freitas IMB and Verspagen B (2017) The motivations, institutions and organization of university-industry collaborations in the Netherlands. Journal of evolutionary economics 27(3): 379-412.

Galan-Muros V and Davey T (2017) The UBC ecosystem: Putting together a comprehensive framework for university-business cooperation. The Journal of Technology Transfer 42(2): 1-36.

Gibb A and Hannon P (2006) Towards the entrepreneurial university. International Journal of Entrepreneurship Education 4(1): 73-110.

Gibb A, Haskins G and Robertson I (2012) Leading the entrepreneurial university: Meeting the entrepreneurial development needs of higher education institutions. In: Universities in change: Springer, pp. 9-45.

Goldfarb B (2008) The effect of government contracting on academic research: Does the source of funding affect scientific output? Research Policy 37(1): 41-58.

Gunasekara C (2006) The generative and developmental roles of universities in regional innovation systems. Science and Public Policy 33(2): 137-150.

Han S-S and Yim D-S (2018) Path Dependence in Industry-University Cooperation-In terms of Industry's Voluntary Participation. International Journal of Industrial Distribution \& Business 9(3): 45-56.

Hasanefendic S, Heitor M and Horta H (2016) Training students for new jobs: The role of technical and vocational higher education and implications for science policy in Portugal. Technological Forecasting and Social Change 113(part B): 328-340.

Healy A, Perkmann M, Goddard J, et al. (2014) Measuring the impact of university-business cooperation. Final report. European Union.

Hemmert M, Bstieler L and Okamuro H (2014) Bridging the cultural divide: Trust formation in universityindustry research collaborations in the US, Japan, and South Korea. Technovation 34(10): 605-616.

Hisrich RD (2006) Entrepreneurship research and education in the world: Past, present and future. In: Jahrbuch Entrepreneurship 2005/06: Springer, pp. 3-14.

Hladchenko M and Pinheiro R (2019) Implementing the Triple Helix Model: Means-Ends Decoupling at the State Level? Minerva 57(1): 1-22.

Hughes A (2011) Open innovation, the Haldane principle and the new production of knowledge: Science policy and university-industry links in the UK after the financial crisis. Prometheus 29(4): 411-442.

Hülsbeck M, Lehmann EE and Starnecker A (2013) Performance of technology transfer offices in Germany. The Journal of Technology Transfer 38(3): 199-215.

Ishengoma E and Vaaland TI (2016) Can university-industry linkages stimulate student employability? Education + Training 58(1): 18-44.

Ivanova IA and Leydesdorff L (2014) A simulation model of the Triple Helix of university-industrygovernment relations and the decomposition of the redundancy. Scientometrics 99(3): 927-948.

Jongbloed B and Vossensteyn H (2016) University funding and student funding: International comparisons. Oxford Review of Economic Policy 32(4): 576-595.

Kaklauskas A, Banaitis A, Ferreira F, et al. (2018) An evaluation system for university-Industry partnership sustainability: Enhancing options for entrepreneurial universities. Sustainability 10(1): 119-132.

Kaymaz K and Eryiğit KY (2011) Determining factors hindering university-industry collaboration: An analysis from the perspective of academicians in the context of entrepreneurial science paradigm. International Journal of Social Inquiry 4(1): 185-213.

Lahorgue MA (2009) Managing Relations with Industry. Higher Education Management and Policy 17(2): 127137. 
Lam A (2011) What motivates academic scientists to engage in research commercialization: 'Gold', 'ribbon' or 'puzzle'? Research Policy 40(10): 1354-1368.

Laukkanen M (2003) Exploring academic entrepreneurship: Drivers and tensions of university-based business. Journal of Small Business and Enterprise Development 10(4): 372-382.

Leydesdorff L, Etzkowitz H, Ivanova I, et al. (2017) The Measurement of Synergy in Innovation Systems: Redundancy Generation in a Triple Helix of University-Industry-Government Relations.

Leydesdorff L and Ivanova I (2016) "Open innovation" and "triple helix" models of innovation: Can synergy in innovation systems be measured? Journal of Open Innovation: Technology, Market, and Complexity 2(11): $1-12$.

Lichtenthaler U (2005) External commercialization of knowledge: Review and research agenda. International Journal of Management Reviews 7(4): 231-255.

Lincoln YS and Guba EG (1985) Naturalistic inquiry. Beverly Hills, CA: Sage Publications.

Malik TH (2013) National institutional differences and cross-border university-industry knowledge transfer. Research Policy 42(3): 776-787.

Maresch D, Harms R, Kailer N, et al. (2016) The impact of entrepreneurship education on the entrepreneurial intention of students in science and engineering versus business studies university programs. Technological Forecasting and Social Change 104: 172-179.

Mars MM, Bronstein JL and Lusch RF (2012) The value of a metaphor: Organizations and ecosystems. Organizational Dynamics 41(4): 271-280.

Mascarenhas C, Ferreira JJ and Marques C (2018) University-industry cooperation: A systematic literature review and research agenda. Science and Public Policy 45(5): 708-718.

McNichols D (2010) Optimal knowledge transfer methods: A Generation X perspective. Journal of knowledge management 14(1): 24-37.

Metcalfe JS (2010) University and Business Relations: Connecting the Knowledge Economy. Minerva 48(1): 533.

Meyer JW (2010) World society, institutional theories, and the actor. Annual review of sociology 36: 1-20.

Miles MB and Huberman AM (1994) Qualitative data analysis: An expanded sourcebook. Beverly Hills, CA: Sage Publications.

Miller K, McAdam R, Moffett S, et al. (2016) Knowledge transfer in university quadruple helix ecosystems: An absorptive capacity perspective. $R \& D$ Management 46(2): 383-399.

Muscio A (2007) The impact of absorptive capacity on SMEs' collaboration. Economics of Innovation and New Technology 16(8): 653-668.

Narula R (2004) R\&D collaboration by SMEs: New opportunities and limitations in the face of globalisation. Technovation 24(2): 153-161.

Nonaka I (1994) A Dynamic Theory of Organizational Knowledge Creation. Organization Science 5(1): 14-37.

Nyman GS (2015) University-business-government collaboration: From institutes to platforms and ecosystems. Triple Helix 2(2): 1-20.

Orazbayeva B, Davey T, Plewa C, et al. (2019) Engagement of academics in education-driven universitybusiness cooperation: A motivation-based perspective. Studies in Higher Education: 1-14. Retrived from: doi.org/10.1080/03075079.2019.1582013.

Ostrom AL, Parasuraman A, Bowen DE, et al. (2015) Service research priorities in a rapidly changing context. Journal of Service Research 18(2): 127-159.

Partha D and David PA (1994) Toward a new economics of science. Research Policy 23(5): 487-521.

Pavlin S (2016) Considering University-Business Cooperation Modes from the Perspective of Enterprises. European Journal of Education 51(1): 25-39.

Perkmann M, Neely A and Walsh K (2011) How should firms evaluate success in university-industry alliances? A performance measurement system. $R \& D$ Management 41(2): 202-216.

Perkmann M, Tartari V, McKelvey M, et al. (2013) Academic engagement and commercialisation: A review of the literature on university-industry relations. Research Policy 42(2): 423-442.

Perkmann M and Walsh K (2007) University-industry relationships and open innovation: Towards a research agenda. International Journal of Management Reviews 9(4): 259-280.

Plewa C, Galán-Muros V and Davey T (2015) Engaging business in curriculum design and delivery: A higher education institution perspective. Higher Education 70(1): 35-53 (accessed 17 August 2017).

Plewa C, Korff N, Baaken T, et al. (2013) University-industry linkage evolution: An empirical investigation of relational success factors. $R \& D$ Management 43(4): 365-380.

Plewa C and Quester P (2007) Key drivers of university-industry relationships: The role of organisational compatibility and personal experience. Journal of Services Marketing 21(5): 370-382.

Pujol-Jover M, Riera-Prunera C and Abio G (2015) Competences acquisition of university students: Do they match job market's needs? Intangible Capital 11(4): 612-626. 
Quintana CDD, Mora J-G, Pérez PJ, et al. (2016) Enhancing the development of competencies: The role of UBC. European Journal of Education 51(1): 10-24.

Rajalo S and Vadi M (2017) University-industry innovation collaboration: Reconceptualization. Technovation 62: 42-54.

Ramli MF and Senin AA (2015) Success factors to reduce orientation and resources-related barriers in university-industry R\&D Collaboration particularly during development research stages. Procedia - Social and Behavioral Sciences 172: 375-382.

Ramos-Vielba I, Fernández-Esquinas M and Espinosa-de-los-Monteros E (2010) Measuring university-industry collaboration in a regional innovation system. Scientometrics 84(3): 649-667.

Rampersad G, Quester P and Troshani I (2010) Examining network factors: Commitment, trust, coordination and harmony. Journal of Business \& Industrial Marketing 25(7): 487-500 (accessed 26 July 2017).

Rasmussen E and Wright M (2015) How can universities facilitate academic spin-offs? An entrepreneurial competency perspective. The Journal of Technology Transfer 40(5): 782-799.

Rhodes J, Hung R, Lok P, et al. (2008) Factors influencing organizational knowledge transfer: Implication for corporate performance. Journal of knowledge management 12(3): 84-100.

Ripoll Feliu V and Díaz Rodríguez A (2017) Knowledge transfer and university-business relations: Current trends in research. Intangible Capital 13(4): 697-719.

Rybnicek R and Königsgruber R (2019) What makes industry-university collaboration succeed? A systematic review of the literature. Journal of Business Economics 89(2): 221-250.

Sandberg J, Holmström J, Napier N, et al. (2015) Balancing diversity in innovation networks: Trading zones in university-industry R\&D collaboration. European Journal of Innovation Management 18(1): 44-69.

Sarpong D, AbdRazak A, Alexander E, et al. (2015) Organizing practices of university, industry and government that facilitate (or impede) the transition to a hybrid triple helix model of innovation. Technological Forecasting and Social Change 123: 142-152.

Schartinger D, Rammer C, Fischer MM, et al. (2002) Knowledge interactions between universities and industry in Austria: Sectoral patterns and determinants. Research Policy 31(3): 303-328.

Siegel DS, Waldman D and Link A (2003) Assessing the impact of organizational practices on the relative productivity of university technology transfer offices: An exploratory study. Research Policy 32(1): 27-48.

Skute I, Zalewska-Kurek K, Hatak I, et al. (2017) Mapping the field: A bibliometric analysis of the literature on university-industry collaborations. The Journal of Technology Transfer: 1-32.

Teixeira AAC and Mota L (2012) A bibliometric portrait of the evolution, scientific roots and influence of the literature on university-industry links. Scientometrics 93(3): 719-743.

Tijssen RJW, van Leeuwen TN and van Wijk E (2009) Benchmarking university-industry research cooperation worldwide: Performance measurements and indicators based on co-authorship data for the world's largest universities. Research Evaluation 18(1): 13-24.

Tijssen RJW, Yegros-Yegros A and Winnink JJ (2016) University-industry R\&D linkage metrics: Validity and applicability in world university rankings. Scientometrics 109(2): 677-696.

Wilson T (2012) A review of business-university collaboration. London: Department for Business, Innovation and Skills. 

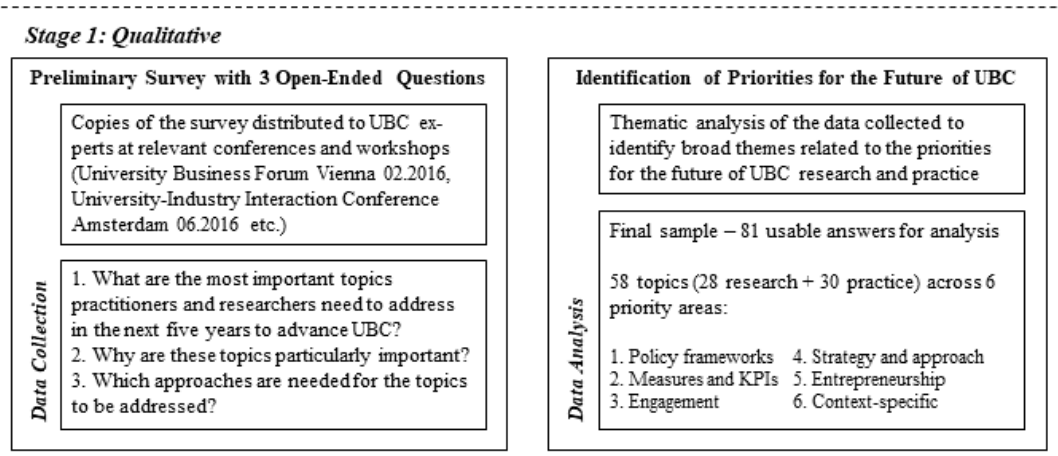

Stage 2: Quantitative
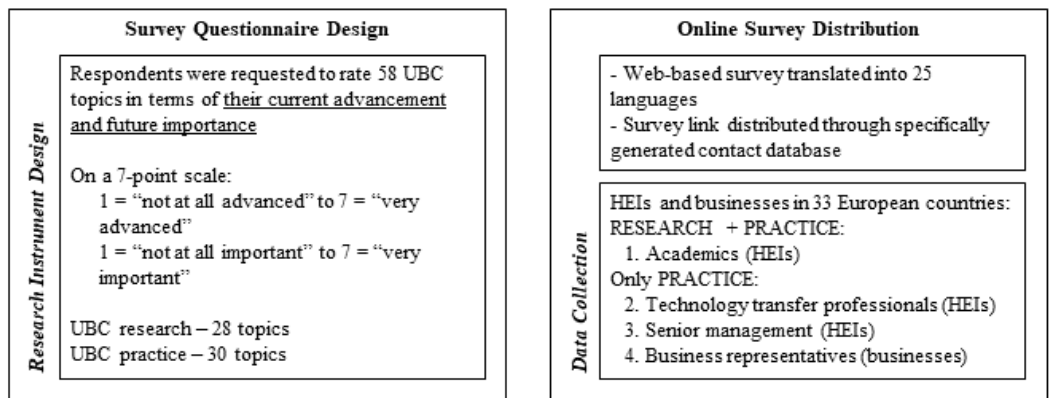

\begin{tabular}{|c|c|}
\hline & Final Sample and Data Analysis \\
\hline 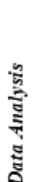 & $\begin{array}{l}\text { The survey lead to a final usable sample of } \\
1190 \text { responses of: } \\
-230 \text { HEI managers } \\
-447 \text { academics } \\
-135 \text { technology transfer professionals } \\
\text { - } 378 \text { business representatives } \\
\text { Data analysis employed descriptive statistics }\end{array}$ \\
\hline
\end{tabular}

Figure 1. Summary of process used in developing UBC research and practice priorities

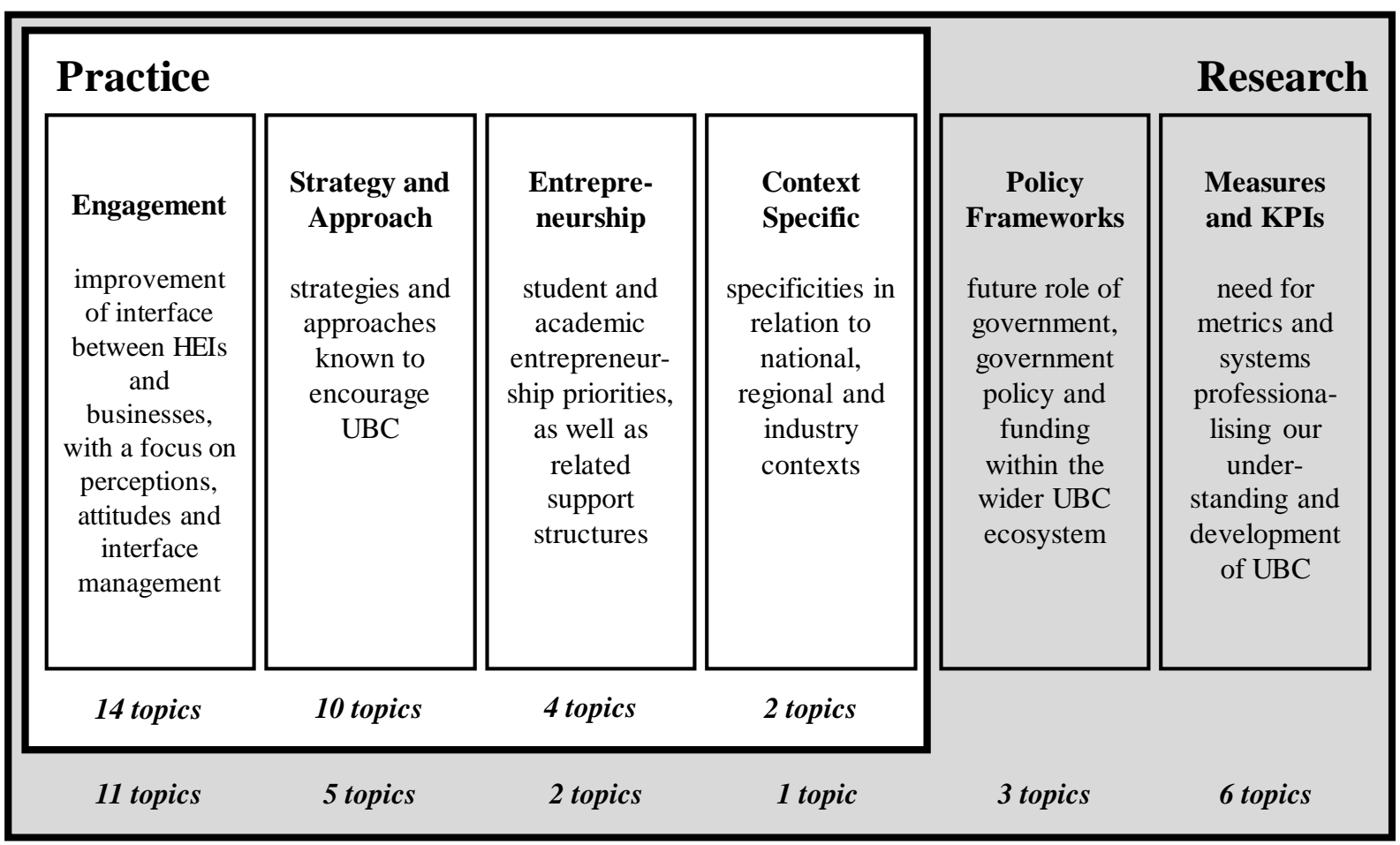

Figure 2. Framework of research and practice priority areas 
Table 1. Areas of UBC Research - quantitative results

\begin{tabular}{|l|c|c|c|c|c|}
\cline { 2 - 6 } \multicolumn{1}{c|}{} & Abbrev. & $\begin{array}{c}\text { No. of } \\
\text { topics }\end{array}$ & $\begin{array}{c}\text { Future } \\
\text { importance }\end{array}$ & $\begin{array}{c}\text { Current } \\
\text { advancement }\end{array}$ & $\begin{array}{c}\text { Degree of priority } \\
\text { ('gap') }\end{array}$ \\
\hline Policy frameworks & PolFra & 3 & 5.8 & 2.7 & 3.1 \\
\hline Measures and KPIs & KPIs & 6 & 5.6 & 2.6 & 3 \\
\hline Strategies and approaches & S\&A & 5 & 5.6 & 2.8 & 2.8 \\
\hline Context-related & Con & 1 & 5.6 & 2.8 & 2.8 \\
\hline Engagement & Eng & 11 & 5.4 & 2.8 & 2.6 \\
\hline Entrepreneurship & Ent & 2 & 5.5 & 3.1 & 2.4 \\
\hline
\end{tabular}

Priorities were assessed on a 7-point Likert scale: $1=$ "not at all advanced" and "not at all important", to $7=$ "very advanced" and "very important" respectively.

Table 2. Topics of UBC Research - quantitative results

UBC Research Domain Topics

\begin{tabular}{|c|c|c|c|c|c|c|}
\hline & & $\begin{array}{l}\text { Futur } \\
\text { impor }\end{array}$ & Ince & $\begin{array}{l}\text { Currer } \\
\text { advanc }\end{array}$ & ment & \\
\hline & UBC Research Domain Topics & Mean & SD & Mean & SD & Gap \\
\hline PolFra & $\begin{array}{l}\text { Exploring the effect of university funding model } \\
\text { changes }\end{array}$ & 6.0 & 1.4 & 2.6 & 1.4 & $3.4 * * *$ \\
\hline KPIs & Understanding the impact of UBC on research & 5.9 & 1.4 & 2.8 & 1.4 & $3.1 * * *$ \\
\hline S\&A & $\begin{array}{l}\text { Developing innovative business / partnership } \\
\text { models for UBC }\end{array}$ & 5.9 & 1.3 & 2.8 & 1.3 & $3.1 * * *$ \\
\hline S\&A & $\begin{array}{l}\text { Developing innovative business / partnership } \\
\text { models for HEI engagement with SMEs }\end{array}$ & 5.8 & 1.4 & 2.8 & 1.3 & $3.0 * * *$ \\
\hline KPIs & $\begin{array}{l}\text { Investigating how business identify and evaluate } \\
\text { suitable researchers / teams }\end{array}$ & 5.6 & 1.6 & 2.6 & 1.4 & $3.0 * * *$ \\
\hline KPIs & Exploring how business define success in UBC & 5.6 & 1.7 & 2.6 & 1.4 & $3.0 * * *$ \\
\hline Eng & Exploring how to encourage academic engagement & 5.7 & 1.5 & 2.7 & 1.4 & $3.0 * * *$ \\
\hline PolFra & Understanding the broader ecosystem of UBC & 5.7 & 1.6 & 2.7 & 1.5 & $3.0 * * *$ \\
\hline S\&A & Understanding how academics are trained for UBC & 5.4 & 1.6 & 2.5 & 1.4 & $2.9 * * *$ \\
\hline KPIs & $\begin{array}{l}\text { Developing KPI systems for academics related to } \\
\text { UBC }\end{array}$ & 5.4 & 1.8 & 2.5 & 1.4 & $2.9 * * *$ \\
\hline KPIs & Measuring the impact of UBC & 5.7 & 1.5 & 2.8 & 1.5 & $2.9 * * *$ \\
\hline KPIs & $\begin{array}{l}\text { Developing metrics for UBC that take into account } \\
\text { organisational differences }\end{array}$ & 5.4 & 1.8 & 2.5 & 1.4 & $2.9 * * *$ \\
\hline S\&A & Exploring business motivations for UBC & 5.7 & 1.4 & 2.9 & 1.4 & $2.8 * * *$ \\
\hline
\end{tabular}




\begin{tabular}{|c|c|c|c|c|c|c|}
\hline Eng & $\begin{array}{l}\text { Understanding the attitude and skills of great UBC } \\
\text { practitioners }\end{array}$ & 5.6 & 1.5 & 2.8 & 1.5 & $2.8 * * *$ \\
\hline Con & $\begin{array}{l}\text { Investigating UBC across different industry sectors } \\
\text { and cultural contexts }\end{array}$ & 5.6 & 1.6 & 2.8 & 1.5 & $2.8 * * *$ \\
\hline Eng & $\begin{array}{l}\text { Understanding the needs and roles of all } \\
\text { stakeholders in UBC }\end{array}$ & 5.8 & 1.4 & 3.0 & 1.4 & $2.8 * * *$ \\
\hline Eng & Investigating co-learning processes & 5.4 & 1.6 & 2.7 & 1.4 & $2.8 * * *$ \\
\hline PolFra & $\begin{array}{l}\text { Exploring the role of government in the triple helix } \\
\text { (HEI. business. government) }\end{array}$ & 5.6 & 1.6 & 2.8 & 1.6 & $2.8 * * *$ \\
\hline Eng & $\begin{array}{l}\text { Exploring risks and ways of minimizing risks } \\
\text { associated with UBC }\end{array}$ & 5.4 & 1.6 & 2.7 & 1.4 & $2.6 * * *$ \\
\hline Eng & $\begin{array}{l}\text { Conducting cost-benefit analysis of different IP } \\
\text { models }\end{array}$ & 5.4 & 1.7 & 2.8 & 1.5 & $2.6 * * *$ \\
\hline Ent & Exploring ways of cultivating academic spin-offs & 5.6 & 1.7 & 3.0 & 1.6 & $2.6 * * *$ \\
\hline Eng & $\begin{array}{l}\text { Investigating the effect of different foci between } \\
\text { HEI and business }\end{array}$ & 5.4 & 1.6 & 2.8 & 1.5 & $2.5 * * *$ \\
\hline Eng & $\begin{array}{l}\text { Exploring the management of relationships over } \\
\text { time }\end{array}$ & 5.2 & 1.7 & 2.8 & 1.4 & $2.4 * * *$ \\
\hline S\&A & Exploring HEI motivations for UBC & 5.4 & 1.6 & 2.9 & 1.4 & $2.4 * * *$ \\
\hline Eng & Developing models of communication for UBC & 5.3 & 1.7 & 2.9 & 1.4 & $2.4^{* * * *}$ \\
\hline Ent & Exploring the role of entrepreneurship for students & 5.4 & 1.7 & 3.1 & 1.6 & $2.3 * * *$ \\
\hline Eng & Understanding cultural barriers & 5.3 & 1.7 & 3.0 & 1.6 & $2.3 * * *$ \\
\hline Eng & $\begin{array}{l}\text { Exploring extant stereotypes and assumptions } \\
\text { relating to UBC }\end{array}$ & 5.1 & 1.7 & 2.8 & 1.5 & $2.3 * * *$ \\
\hline
\end{tabular}

Table 3. Areas of UBC practice - quantitative results

\begin{tabular}{|l|c|c|c|c|c|}
\cline { 2 - 5 } \multicolumn{1}{c|}{} & Abbrev. & $\begin{array}{c}\text { No. of } \\
\text { topics }\end{array}$ & $\begin{array}{c}\text { Future } \\
\text { importance }\end{array}$ & $\begin{array}{c}\text { Current } \\
\text { advancement }\end{array}$ & $\begin{array}{c}\text { Degree of priority } \\
\text { ('gap') }\end{array}$ \\
\hline Context-related priorities & Con & 2 & 5.6 & 3 & 2.5 \\
\hline Strategies and approaches & S\&A & 10 & 5.7 & 3.3 & 2.4 \\
\hline Entrepreneurship & Ent & 4 & 5.8 & 3.4 & 2.4 \\
\hline Engagement & Eng & 14 & 5.7 & 3.3 & 2.3 \\
\hline
\end{tabular}

Priorities were assessed on a 7-point Likert scale: $1=$ "not at all advanced" and "not at all important", to 7 = "very advanced" and "very important" respectively. 
Table 4. Topics of UBC practice - quantitative results

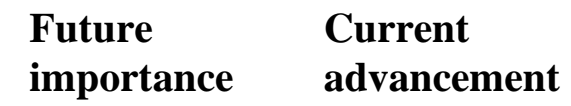

UBC Practice Domain Topics

Mean SD Mean SD Gap

\begin{tabular}{|c|c|c|c|c|c|c|}
\hline S\&A & $\begin{array}{l}\text { Enabling academics to take meaningful amount of time } \\
\text { for industry engagement }\end{array}$ & 5.8 & 1.3 & 2.9 & 1.5 & $2.9 * * *$ \\
\hline Ent & $\begin{array}{l}\text { Developing an entrepreneurial mindset in HEI staff } \\
\text { and students }\end{array}$ & 5.9 & 1.4 & 3.2 & 1.6 & $2.7 * * *$ \\
\hline S\&A & Implementing a research culture open to UBC & 6 & 1.2 & 3.4 & 1.5 & $2.6 * * *$ \\
\hline Eng & Fostering HEI cooperation with SMEs & 6 & 1.2 & 3.4 & 1.4 & $2.6 * * *$ \\
\hline Ent & Fostering staff entrepreneurship at the HEI & 5.7 & 1.5 & 3.1 & 1.6 & $2.6 * * *$ \\
\hline S\&A & Fostering UBC beyond a mere technology focus & 5.8 & 1.4 & 3.2 & 1.4 & $2.6 * * *$ \\
\hline S\&A & $\begin{array}{l}\text { Developing a comprehensive. coordinated approach to } \\
\text { engaging with business }\end{array}$ & 5.9 & 1.4 & 3.3 & 1.4 & $2.6 * * *$ \\
\hline Con & Fostering UBC in economically weak regions & 5.6 & 1.6 & 3 & 1.5 & $2.5 * * *$ \\
\hline S\&A & Approaching UBC with flexibility and transparency & 6 & 1.3 & 3.5 & 1.5 & $2.5 * * *$ \\
\hline Eng & $\begin{array}{l}\text { Promoting benefits of UBC for business and the wider } \\
\text { community }\end{array}$ & 5.8 & 1.3 & 3.3 & 1.5 & $2.5 * * *$ \\
\hline Eng & Developing HEI recruitment strategy for UBC & 5.5 & 1.5 & 3 & 1.5 & $2.5 * * *$ \\
\hline Eng & Promoting career perspectives for TTO staff & 5.6 & 1.5 & 3.1 & 1.5 & $2.5 * * *$ \\
\hline Eng & $\begin{array}{l}\text { Developing strong relationships between HEIs and } \\
\text { business }\end{array}$ & 6.1 & 1.1 & 3.7 & 1.5 & $2.5 * * *$ \\
\hline Eng & Ensuring successful stakeholder management & 5.8 & 1.3 & 3.4 & 1.4 & $2.4 * * *$ \\
\hline Eng & Managing stakeholder expectations & 5.6 & 1.4 & 3.1 & 1.4 & $2.4 * * *$ \\
\hline S\&A & Promoting UBC proactively & 5.8 & 1.4 & 3.5 & 1.5 & $2.4 * * *$ \\
\hline Eng & Ensuring strong governance of UBC partnerships & 5.6 & 1.5 & 3.3 & 1.4 & $2.3 * * *$ \\
\hline Eng & $\begin{array}{l}\text { Offering dual education programs including time at } \\
\text { university and business }\end{array}$ & 5.5 & 1.5 & 3.2 & 1.6 & $2.3 * * *$ \\
\hline Eng & Employing highly qualified TTO staff & 5.7 & 1.4 & 3.5 & 1.6 & $2.2 * * *$ \\
\hline Eng & Utilising UBC to enhance student employability & 5.9 & 1.4 & 3.7 & 1.6 & $2.2 * * *$ \\
\hline S\&A & $\begin{array}{l}\text { Offering business a single or easy access point to the } \\
\text { HEI }\end{array}$ & 5.5 & 1.6 & 3.3 & 1.5 & $2.2 * * *$ \\
\hline
\end{tabular}




\begin{tabular}{|c|l|c|c|c|c|c|}
\hline Con & $\begin{array}{l}\text { Understanding cultural differences related to UBC } \\
\text { across countries (e.g. in EU) }\end{array}$ & 5.5 & 1.5 & 3.2 & 1.5 & $\mathbf{2 . 2} * * *$ \\
\hline S\&A & Increasing the number of shared appointments & 5.2 & 1.6 & 3 & 1.4 & $\mathbf{2 . 2} * * *$ \\
\hline Ent & Fostering student entrepreneurship at the HEI & 5.8 & 1.5 & 3.6 & 1.6 & $\mathbf{2 . 2} * * *$ \\
\hline Eng & Optimizing model for IP development / ownership & 5.6 & 1.5 & 3.4 & 1.5 & $\mathbf{2 . 2} * * *$ \\
\hline S\&A & $\begin{array}{l}\text { Optimizing the business models for entities enabling } \\
\text { UBC (such as TTOs) }\end{array}$ & 5.4 & 1.5 & 3.3 & 1.5 & $\mathbf{2 . 1}^{* * *}$ \\
\hline Ent & $\begin{array}{l}\text { Creating incubators and accelerators connecting HEI } \\
\text { and business }\end{array}$ & 5.7 & 1.5 & 3.6 & 1.7 & $\mathbf{2 . 1} * * *$ \\
\hline Eng & Overcoming cultural differences & 5.5 & 1.6 & 3.4 & 1.5 & $\mathbf{2 . 1} * * *$ \\
\hline S\&A & $\begin{array}{l}\text { Allowing greater flexibility in timeframes of degree } \\
\text { programs and their components }\end{array}$ & 5.2 & 1.7 & 3.1 & 1.5 & $\mathbf{2 . 1} * * *$ \\
\hline Eng & Creating multi-organisational networks for UBC & 5.3 & 1.6 & 3.2 & 1.5 & $\mathbf{2 . 1} * * *$ \\
\hline
\end{tabular}


Table 5. A future research agenda for UBC

\begin{tabular}{|c|c|}
\hline Policy frameworks & $\begin{array}{l}\text { - What effect do previous, current or potential university funding model } \\
\text { changes have on the scale and success of UBC? How can these effects } \\
\text { best be modelled across various actors within the triple helix and the } \\
\text { broader society? } \\
\text { - What does a supportive and successful UBC ecosystem look like? What } \\
\text { actors, processes institutions or other factors within the ecosystem } \\
\text { inhibit or facilitate UBC? } \\
\text { - What role do policy makers have in the triple helix? Which policy levers } \\
\text { and mechanisms hinder versus encourage UBC? }\end{array}$ \\
\hline Measures and KPIs & $\begin{array}{l}\text { - What impact does UBC have on the universities' and researchers' } \\
\text { selection of research themes? Has research changed with the } \\
\text { increasing focus on UBC and, if yes, how? } \\
\text { - How do businesses identify suitable researchers, teams and } \\
\text { universities? Once identified, how do they evaluate different options } \\
\text { for research partners? Does this differ across different types of } \\
\text { businesses or across industries? } \\
\text { - How do businesses define and measure success in UBC? Which } \\
\text { frameworks are utilized currently and how have these evolved over } \\
\text { time? Where do business see the future of their evaluations of } \\
\text { university partners go in the future? } \\
\text { - What KPI systems have been developed for academics in relation to } \\
\text { UBC? How do they differ across various types of universities and } \\
\text { countries? In what way do we see a general move towards a more } \\
\text { engagement-focused KPI system? } \\
\text { Which metrics can be utilized to benchmark UBC while taking into } \\
\text { account organizational differences? Which types of difference are } \\
\text { relevant to consider? }\end{array}$ \\
\hline $\begin{array}{l}\text { Strategies and } \\
\text { approaches }\end{array}$ & $\begin{array}{l}\text { What is the effectiveness of existing business and partnership models } \\
\text { for UBC? How can the analysis of current models stimulate thinking } \\
\text { around new and improved models for the future? Specifically, what } \\
\text { should models for effective university-SME engagement look like? } \\
\text { - How are academics currently trained for UBC? What is working and } \\
\text { what is missing? How can we optimize such training offerings to } \\
\text { maximize capability development? } \\
\text { - What motivates various types of businesses and HEIs to engage in } \\
\text { institutions and different ways of engaging in UBC? }\end{array}$ \\
\hline Engagement & $\begin{array}{l}\text { - How can academic involvement in UBC best be encouraged and } \\
\text { incentivized, taking into account various characteristics of an academic, } \\
\text { an academic's employment and experience as well as various types of } \\
\text { UBC } \\
\text { - Which skills and attitudes characterize practitioners most successful at } \\
\text { facilitating UBC? How do these practitioners relate to the business and } \\
\text { academics? Under which circumstances are certain skills, attitudes, } \\
\text { interactions, processes and structures best suited to facilitate UBC? }\end{array}$ \\
\hline
\end{tabular}




\begin{tabular}{|c|c|}
\hline & $\begin{array}{l}\text { - What are the needs and roles of various UBC stakeholders? How can } \\
\text { they be identified and how do they relate to each other? } \\
\text { - How do stakeholders co-learn in UBC? How can such co-learning best } \\
\text { be facilitated? How does co-learning affect the success of UBC? } \\
\text { - How does risk and risk management influence UBC and what can be } \\
\text { learn from the risk management literature to advance our understanding } \\
\text { of this area in the context of UBC? } \\
\text { - What does cost-benefit analysis tell us about various IP models? } \\
\text { - How relationships between HEI and business be improved, considering } \\
\text { different foci, relationship evolution over time, models of } \\
\text { communication, cultural barriers, as well as stereotypes and } \\
\text { assumptions? What perspectives do various actors in the triple helix } \\
\text { have and how do they compare? }\end{array}$ \\
\hline Entrepreneurship & $\begin{array}{l}\text { - How can academic spin-offs be cultivated more effectively? } \\
\text { In a changing higher education landscape, what role does } \\
\text { entrepreneurship have for students? How are mindsets and skills being } \\
\text { developed? What effect do changes in entrepreneurship education have } \\
\text { on student recruitment, employability, self-employment and workforce } \\
\text { development? }\end{array}$ \\
\hline $\begin{array}{l}\text { Context-related } \\
\text { priority }\end{array}$ & $\begin{array}{l}\text { - How does UBC differ across various industries and across cultures? } \\
\text { Which situational factors should be considered in future research } \\
\text { projects? }\end{array}$ \\
\hline
\end{tabular}


Table 6: A future practice agenda for UBC

\begin{tabular}{|c|c|}
\hline $\begin{array}{l}\text { Strategies and } \\
\text { approaches }\end{array}$ & $\begin{array}{l}\text { Provide academics with the ability to participate meaningfully in } \\
\text { industry engagement. What does this time requirement depend on? } \\
\text { How can time be freed amongst various demands on academics? } \\
\text { Ensure a culture open to UBC. How can the various stakeholders in } \\
\text { the triple helix foster such culture, across both technology-related and } \\
\text { other areas? } \\
\text { - Develop a simple access point, supported by an effective and } \\
\text { comprehensive service system. How can the HEI offer a single and } \\
\text { easy access point for businesses, with internal institutional } \\
\text { mechanisms, structures and systems ensuring a comprehensive, } \\
\text { coordinated and transparent institutional approach? How can } \\
\text { flexibility required within and for individual partnerships be enabled } \\
\text { as part of this system? } \\
\text { - Proactively promote UBC. What are the best mechanisms to promote } \\
\text { UBC internally and externally, by any or all actors in the triple helix? } \\
\text { Expand mechanisms facilitating UBC. How can shared appointments } \\
\text { across the triple helix be scaled? What are the roles of the different } \\
\text { actors in achieving this? } \\
\text { Be innovative in the development of suitable business models. What } \\
\text { can innovative business models look like for various entities enabling } \\
\text { UBC, and how can they best connect to maximize benefits from } \\
\text { UBC? } \\
\text { Future-proof learning offerings. How can degree programs be } \\
\text { developed in a more flexible manner to better cater for a more diverse } \\
\text { community of lifelong learners? }\end{array}$ \\
\hline Entrepreneurship & $\begin{array}{l}\text { Develop an entrepreneurial mindset widely. How can HEIs best } \\
\text { develop an entrepreneurial mindset amongst staff and students? How } \\
\text { should the shift in mindset be determined and evidenced? } \\
\text { - Encourage entrepreneurial activity. How can academic staff and } \\
\text { students best be enabled, encouraged and incentives to act } \\
\text { entrepreneurially? Which methods have been most successful to date? } \\
\text { How can we achieve a step change in entrepreneurial activity? }\end{array}$ \\
\hline Engagement & $\begin{array}{l}\text { - Scale SME engagement. How can all actors within the triple helix } \\
\text { contribute to scaling SME engagement with HEI? How can the } \\
\text { readiness of SMEs to engage with HEIs be advanced? How do HEIs } \\
\text { adapt to maximize mutual value in their interactions with SMEs? How } \\
\text { can policy makers best support the scaling of SME-focused UBC? } \\
\text { - Communicate the potential benefits and types of UBC to businesses } \\
\text { and the community. How can UBC and potential benefits best be } \\
\text { promoted to business and the broader community? What are the best } \\
\text { messages, message sources and message channels for the diverse target } \\
\text { audiences? } \\
\text { Develop the workforce that is best able to advance UBC. How can } \\
\text { recruitment and career progression optimized to ensure the best } \\
\text { possible workforce to drive UBC (in relation to academics, } \\
\text { professional and specifically TTO staff)? }\end{array}$ \\
\hline
\end{tabular}




\begin{tabular}{|c|c|}
\hline & $\begin{array}{l}\text { - Improve stakeholder management. How can the management of } \\
\text { stakeholders and of the expectations of those stakeholders be improved } \\
\text { both on an individual and institutional level? } \\
\text { - Integration of UBC across learning and teaching. How can UBC be } \\
\text { better integrated, e.g. through dual education offerings, to enhance } \\
\text { student employability? } \\
\text { - Find the best IP ownership model. How can IP development / } \\
\text { ownership models be optimized with the view of improving mutual } \\
\text { benefit and scalability? } \\
\text { - Identify and overcome cultural differences that hinder improvements. } \\
\text { How can cultural differences be overcome? }\end{array}$ \\
\hline $\begin{array}{l}\text { Context-related } \\
\text { priority }\end{array}$ & $\begin{array}{l}\text { Encourage UBC in economically weak regions. What are the best } \\
\text { ways to foster UBC in various regions? What form should UBC take } \\
\text { and what mechanisms would be most suited? } \\
\text { - Consider national culture differences in the design of support } \\
\text { mechanisms. How can learnings from other countries and cultures be } \\
\text { adapted to other countries or regions? Which cultural factors are most } \\
\text { relevant? }\end{array}$ \\
\hline
\end{tabular}

